\title{
Spatial Relationships of Soil Texture and Crop Rotation to Aspergillus flavus Community Structure in South Texas
}

\author{
Ramon Jaime-Garcia and Peter J. Cotty
}

First and second authors: The University of Arizona, Division of Plant Pathology \& Microbiology, Tucson 85721; and second author: U.S. Department of Agriculture-Agricultural Research Service, Tucson, AZ 85721.

Accepted for publication 31 January 2006.

\begin{abstract}
Jaime-Garcia, R., and Cotty, P. J. 2006. Spatial relationships of soil texture and crop rotation to Aspergillus flavus community structure in South Texas. Phytopathology 96:599-607.

Aspergillus flavus, the causal agent of aflatoxin contamination of cottonseed, is a natural inhabitant of soils. A. flavus can be divided into the $\mathrm{S}$ and $\mathrm{L}$ strains, of which the S-strain isolates, on average, produce greater quantities of aflatoxins than the L-strain isolates. Aflatoxin contamination can be severe in several crops in South Texas. The structure of A. flavus communities residing in soils of South Texas was determined from 326 soil samples collected from 152 fields located from the Rio Grande Valley in the south to Fort Bend County in the north from 2001 through 2003. Analysis of variance indicated significant differences in the incidence of A. flavus isolates belonging to the $\mathrm{S}$ strain (percent $\mathrm{S}$ ) among

significantly higher percent $\mathrm{S}$ incidence than the Rio Grande Valley (4.8\%). No significant differences in percent $S$ among years were detected. The CFU per gram of soil were not significantly different among regions. Strain S incidence was positively correlated with clay content and negatively correlated with sand content. Fields cropped to cotton the previous year had a higher S-strain incidence, whereas fields cropped to corn had greater total quantities of A. flavus propagules. Maps of S-strain patterns show that the S strain constitutes $>30 \%$ of the overall A. flavus community in the area extending from the central Coastal Bend region to the central Upper Coast region. The west Rio Grande Valley had the lowest S-strain incidence $(<10 \%)$. Geographic variation in S-strain incidence may influence the distribution of aflatoxin contamination in South Texas.
\end{abstract} regions. The Coastal Bend (30.7\%) and Upper Coast (25.5\%) regions had
Additional keywords: GIS, geostatistics, kriging, spatial analysis.
Throughout most of the world, concentrations of aflatoxins, potent toxic and carcinogenic fungal metabolites that frequently contaminate food and feed, are limited by regulation $(28,37)$. Aflatoxins are produced by asexual fungi belonging to Aspergillus section Flavi (8). Soils in areas where contamination is common contain diverse communities of aflatoxin-producing fungi (6). Communities of section Flavi differ by region in both species composition and aflatoxin producing potential. Aspergillus flavus, the most common aflatoxin-producing species, can be divided into two morphotypes that commonly are called strains based on morphological, genetic, and physiologic criteria $(2,4$, $14,15)$. The $S$ strain produces numerous small sclerotia (average diameter $<400 \mu \mathrm{m}$ ) and high levels of aflatoxins, whereas the $\mathrm{L}$ strain produces fewer, larger sclerotia (average diameter $>400 \mu \mathrm{m}$ ) and variable levels of aflatoxin $(4,6,17)$. Some isolates of the $\mathrm{L}$ strain produce no aflatoxin (6). The S strain of A. flavus has been reported as a natural soil inhabitant in several areas worldwide, including Thailand in Southeast Asia (32); Argentina in South America (24); and in Arizona (4,6,25), California (12,13), Texas $(9,18)$, Louisiana, Mississippi, and Alabama (6) in the United States of America.

Cottonseed contributes 15 to $20 \%$ of farmer income from cotton in the United States. Aflatoxin contamination has long been a concern for the U.S. cottonseed industry because a small proportion of aflatoxin in feed is transferred to the milk of dairy cows in the slightly modified form aflatoxin $\mathbf{M}_{1}(1,36)$. Cottonseed is a

Corresponding author: P. J. Cotty; E-mail address: pjcotty@email.arizona.edu

DOI: 10.1094/PHYTO-96-0599

This article is in the public domain and not copyrightable. It may be freely reprinted with customary crediting of the source. The American Phytopathological Society, 2006 preferred feed for dairy cows and regulations in the United States prohibit aflatoxin concentrations $>0.5 \mathrm{ng} / \mathrm{g}$ in milk (29). Milk exceeding that limit may be dumped and the producing dairy placed on quarantine. Because dairies typically pay a premium for cottonseed, in areas where aflatoxin contamination of cottonseed is common, aflatoxin content is the most important factor determining seed value (7). Aflatoxin contamination of cottonseed costs millions of dollars annually. In the United States, contamination of cottonseed is most severe in the desert production regions of Arizona and Southern California, and in South Texas $(7,30,33)$.

Spatial patterns of most variables can be described, analyzed, and displayed at any scale with geographic information systems (GIS) and geostatistics. The estimation of values at nonsampled locations is essential to describe variables spatially. Geostatistics adapt classical statistical regression techniques to estimate values at nonsampled locations $(10,19)$ and describe spatial continuity, which can be used to assess uncertainty associated with estimated values (21). Kriging, a geostatistic tool, uses regression techniques for interpolation of spatially correlated data (22). Spatial patterns of the population density and strain composition of A. flavus, the primary causal agent of aflatoxin contamination, $(25,26)$, and of aflatoxin contamination episodes (20) have been described with geostatistics. GIS can be used to capture, manipulate, process, and display spatially distributed data in computers (16). This allows description of objects from the real world in terms of (i) position with respect to a known coordinate system, (ii) relation to environmental variables (i.e., soil type, temperature, disease incidence, or insect density) unrelated to position, and (iii) spatial relationships with each other (topological relations) $(16,34)$.

Both A. flavus community structure and aflatoxin contamination present spatial autocorrelation $(20,25,26)$. However, relationships of contamination to fungal community structure in soils 
have not been described. The objectives of the current study were to (i) spatially analyze the magnitude and strain composition of A. flavus communities in soils of South Texas at different geographic scales, (ii) evaluate influences of crop rotation on community size and structure of $A$. flavus, and (iii) determine relationships of A. flavus community size and structure to soil texture.

\section{MATERIALS AND METHODS}

The structure of A. flavus communities residing in soils of South Texas was determined by analyzing 326 soil samples from 152 fields located from the Rio Grande Valley in the south to Fort Bend County in the north in spring 2001, 2002, and 2003. One to four samples were taken from each field. Soil samples from single-sample fields (88 fields) were taken from a transect of approximately $50 \mathrm{~m}$. Each sample consisted of $>50$ subsamples taken from the soil surface (no deeper than $1 \mathrm{~cm}$ ). In all, 5 to 10 of these subsamples were taken every 10 paces of the transect. Multiple-sample fields (64 fields) were sampled by walking zigzag from one corner toward the opposite corner. The first sample was obtained by walking 50 paces along one side of the field, turning $90^{\circ}$, and walking 50 paces. In all, 50 to 70 subsamples were taken in a 10-pace-radius in this location. From this point, the pacing pattern was repeated until four samples were obtained. The previous season crop was identified for most sampled fields.

Sample processing and isolation of fungi. Soil samples were dried in a forced air oven at 48 to $50^{\circ} \mathrm{C}$ for $48 \mathrm{~h}$ before processing. Dry samples then were placed inside a plastic bag, hammered to break clumps, and passed through a no. 12 sieve (1.7-mm opening). The sieve was vacuumed to remove loose contaminants and washed with ethanol to kill contaminating fungal spores between each sample. Soil texture (percent clay, percent silt, and percent sand) was determined for each sample using the hydrometer method (35). A. flavus was isolated from soil by dilution plating onto a modified Rose Bengal agar (4). For most samples, $10 \mathrm{~g}$ of soil was suspended in $50 \mathrm{ml}$ of autoclaved water by stirring for 20 min. Adjustments in the soil dilution for samples that had either too many or too few CFU in the first isolation were made for subsequent isolations. Isolation plates were incubated for 3 days at $37^{\circ} \mathrm{C}$. For each sample, 12 to 16 discrete Aspergillus section Flavi colonies were subcultured on $5 / 2$ agar (5\% V8 juice and $2 \%$ agar) for 5 to 7 days at $31^{\circ} \mathrm{C}$ and assigned to either the A. flavus $\mathrm{S}$ or L strains, A. tamarii, or A. parasiticus on the basis of colony characteristics and isolate morphology (4). Isolations were made only from plates having $\leq 12$ A. flavus colonies. Quantities of A. flavus in soil were calculated as the number of CFU of A. flavus per gram. The percentage of isolates belonging to the highly aflatoxigenic $\mathrm{S}$ strain of $A$. flavus (percent $\mathrm{S}$ ) was obtained by dividing the number of strain-S isolates by the total number of A. flavus isolates and multiplying by 100 .

Data analysis. The study area was $\approx 450 \mathrm{~km}$ long by $100 \mathrm{~km}$ wide, extending from the Rio Grande Valley in the south to Fort Bend County in the north. The total area was divided into three geographic regions (Rio Grande Valley, Coastal Bend, and Upper Coast). These three regions were subdivided into a total of 11 smaller areas identical to those previously reported (20). The design was unbalanced, with a different number of samples (replicates) per field; therefore, analysis of variance (ANOVA) was performed, using the General Linear Model (GLM) procedure of SAS (version 8.0; SAS Institute, Cary, NC), to assess differences among both regions and areas in the incidence of isolates belonging to the $\mathrm{S}$ strain of $A$. flavus (percent $\mathrm{S}$ ) and the CFU/g of soil. ANOVA also was used to assess the effect of the previous crop on percent $\mathrm{S}$ and $\mathrm{CFU} / \mathrm{g}$. Fields (30\%) that previously were planted to crops other than cotton, corn, or sorghum, or for which there were no previous crop data, were discarded from the previous crop ANOVA analysis. To determine influences of geographic scale (among regions, among areas, among fields, and within fields) on percent $\mathrm{S}, \mathrm{CFU} / \mathrm{g}$, and soil texture (percent clay, percent silt, and percent sand content) variables, a variance components analysis (VCA) in GLM using the VARCOMP procedure of SAS 8.0 with a nested model was performed. The VARCOMP procedure of GLM was used because it best fit the unbalanced design. Pearson's correlation analysis using the CORR procedure of SAS 8.0 was used to determine relationships of both percent $S$ and CFU to soil texture. All the statistical analyses for percent $S$ and $\mathrm{CFU} / \mathrm{g}$ also were performed with transformed data, using square root for percent $S$ and natural logarithm (log) for CFU/g. However, only the $\log$ transformation of $\mathrm{CFU} / \mathrm{g}$ for mean separation was used in the reported results because there was no improvement in the significance levels for other transformations. Tukey's honestly significant difference (HSD) test $(\alpha=0.05)$ was used for means separation on the original data for percent $S$ and on logtransformed data for CFU/g.

Spatial analysis. Soil samples were geo-referenced in the Universal Transverse Mercator (UTM) projected coordinate system. The UTM system gives positions in meters and facilitates correct computation of distances between sample locations in two dimensions. Geostatistical analyses (23) were performed on both percent $\mathrm{S}$ and $\mathrm{CFU} / \mathrm{g}$ to describe patterns of A. flavus in soils throughout South Texas. Spatial patterns of percent $S$ and CFU/g in soils of South Texas as influenced by the previous year crop also were obtained using geostatistics, by subdividing the complete data set based on the previous season's crop. Model variograms, a mathematical description of the spatial autocorrelation, then were developed for percent $\mathrm{S}, \mathrm{CFU}$, and soil texture variables. Omnidirectional experimental variograms were obtained using VARIOWIN 2.21 (27) for percent S and CFU/g. Variogram equations and procedures to develop experimental variograms and fit model variograms followed previously described procedures $(10,11,19,21,22)$. The maximum distance between sample locations was $\approx 450 \mathrm{~km}$ and the minimum distance was $2.5 \mathrm{~km}$.

Kriging and map display. ArcGIS (version 9.0 for Windows; ESRI, Redlands, CA) was used to interpolate values in nonsampled areas by block kriging using model variograms on a 2-by-2-km grid with a search neighborhood of $60,000 \mathrm{~m}$ and a maximum of 40 sample locations. Previously digitized features were used as background for views and layouts of the kriged values.

\section{RESULTS}

A. flavus community structure in soils of South Texas. A. flavus communities in soils of South Texas differed significantly among regions in community density (CFU/g) and S-strain incidence (percent S) (Table 1). Quantities of A. flavus were greater in the Upper Coast $(882 \mathrm{CFU} / \mathrm{g})$ than in the Costal Bend (497 CFU/g) (Table 1). On the other hand, average S-strain incidence was lower in the Rio Grande Valley $(4.8 \%)$ than in either the Coastal Bend $(25.5 \%)$ or Upper Coast $(30.8 \%)$ The Rio Grande Valley and Coastal Bend regions both had significant differences in percent $S$ among years (Table 1). The Rio Grande Valley had higher percent $S$ in 2002 compared with 2001 and the Coastal Bend had higher percent S in 2003 compared with either 2001 or 2002. Significant differences in percent $S$ also occurred among the 11 areas into which the three regions were divided (Table 2). Areas in the east and north of the Coastal Bend and south and central of the Upper Coast had the highest percent $S$.

Variance at different geographic scales. Most variance (93.9\%) for CFU/g is explained by the small geographic scales within and among fields, with among fields explaining $48.4 \%$ and within fields $45.5 \%$ (Table 3 ). Within fields also explained $53.8 \%$ of percent $\mathrm{S}$ variation whereas among fields explained only $13.5 \%$. Among regions explained none of the $\mathrm{CFU} / \mathrm{g}$ variance and $23.7 \%$ of the percent $\mathrm{S}$ variance. Most of the variation 
(67.3 to $90.7 \%$ ) for the soil texture variables clay, silt, and sand occurred among fields (47.4 to 57.4\%) and among areas (19.9 to $34.1 \%)$.

Effect of crop rotation on A. flavus communities in soil. A. flavus communities in soils were studied to determine whether crop rotation influenced the magnitude and composition of A. flavus communities. On average, $\mathrm{CFU} / \mathrm{g}$ was higher in fields where the previous crop was corn $(1,485 \mathrm{CFU} / \mathrm{g})$ compared with either cotton (566 CFU/g) or sorghum (157 CFU/g) (Table 4). In general, these trends held for the individual regions as well. On the other hand, fields in South Texas previously cropped with cotton had more S strain $(28.6 \%)$ than fields previously cropped with corn $(17.0 \%)$. Fields previously cropped to sorghum were intermediate between those cropped to cotton and corn. This trend held on a region-by-region basis, but was significant only in the Coastal Bend.

Soil texture and A. flavus relationship. According to Pearson's correlation analyses, there were significant positive correlations between percent clay and both percent $\mathrm{S}(r=0.28, P<0.0001)$ and CFU/g $(r=0.16, P=0.008)$ and a significant negative correlation between percent sand and both percent $\mathrm{S}(r=-0.28, P<$ $0.0001)$ and $\mathrm{CFU} / \mathrm{g}(r=-0.13, P=0.04)$ (Table 5). Analyses using data averaged by area greatly improved correlation coefficients for percent $\mathrm{S}$ with clay and sand $(r=0.82, P=0.003$ for clay and $r=-0.85, P=0.002$ for sand). Correlation coefficients between CFU/g and soil type content also were improved, but not appreciably ( $r=0.34, P=0.34$ for percent clay and $r=0.20, P=$ 0.58 for percent sand) (Table 5).

Spatial patterns of $A$. flavus community structure in soils of South Texas. Geostatistical analyses, including variogram analyses and surface maps obtained by kriging, indicated patchy distribution of both A. flavus community structure (percent $\mathrm{S}$ and $\mathrm{CFU} / \mathrm{g}$ ) and soil texture (percent clay, sand, and silt).

Variogram analyses. Parameters of modeled variograms for soil and fungal characteristics of fields previously cropped with corn, cotton, sorghum, and other crops are presented in Table 6. Spatial continuity of both percent S and CFU/g was best described by covariograms. All the variograms and covariograms adjusted to the spherical type with an indicative goodness of fit (IGF) ranging from 0.002 to 0.046 based on a weighted mean square standardized. The range of $\mathrm{CFU} / \mathrm{g}$ variograms (covariograms) was much shorter $(30,000$ to $44,000 \mathrm{~m})$ than those given by percent $\mathrm{S}(36,500$ to $75,000 \mathrm{~m})$. Soil samples obtained from fields previously cropped with corn presented the shortest

TABLE 1. CFU of Aspergillus flavus and percentage of isolates of A. flavus belonging to the S strain (percent S) from soil of different regions in South Texas from 2001 to $2003^{2}$

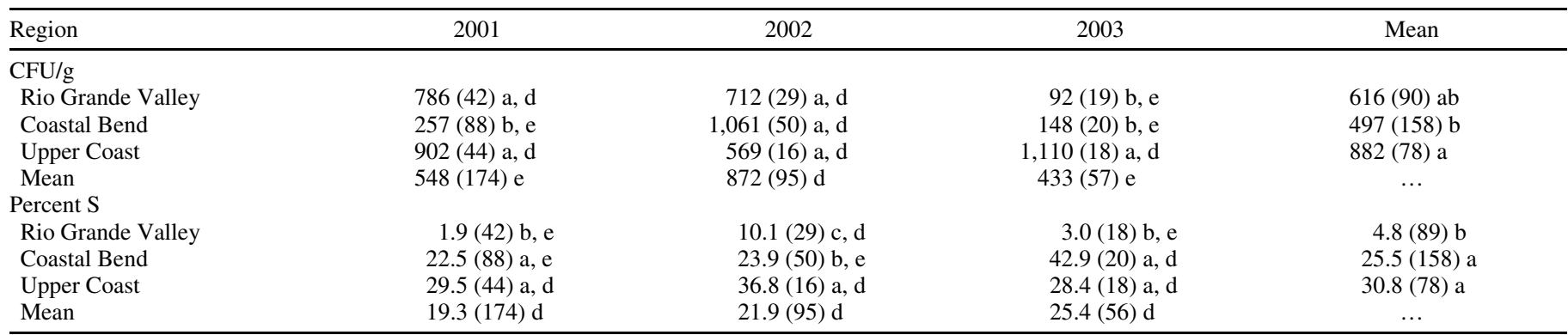

${ }^{\mathrm{z}}$ Numbers in parentheses $=$ number of samples analyzed. Averages with the same letter are not significantly different by Tukey's honestly significant difference test $(\alpha=0.05)$. Letters before the comma indicate differences among regions (rows) and letters following the comma indicate differences among years (columns).

TABLE 2. CFU of Aspergillus flavus and percentage of isolates of A. flavus belonging to the $\mathrm{S}$ strain (percent $\mathrm{S}$ ) from soil of different areas in South Texas from 2001 to $2003^{2}$

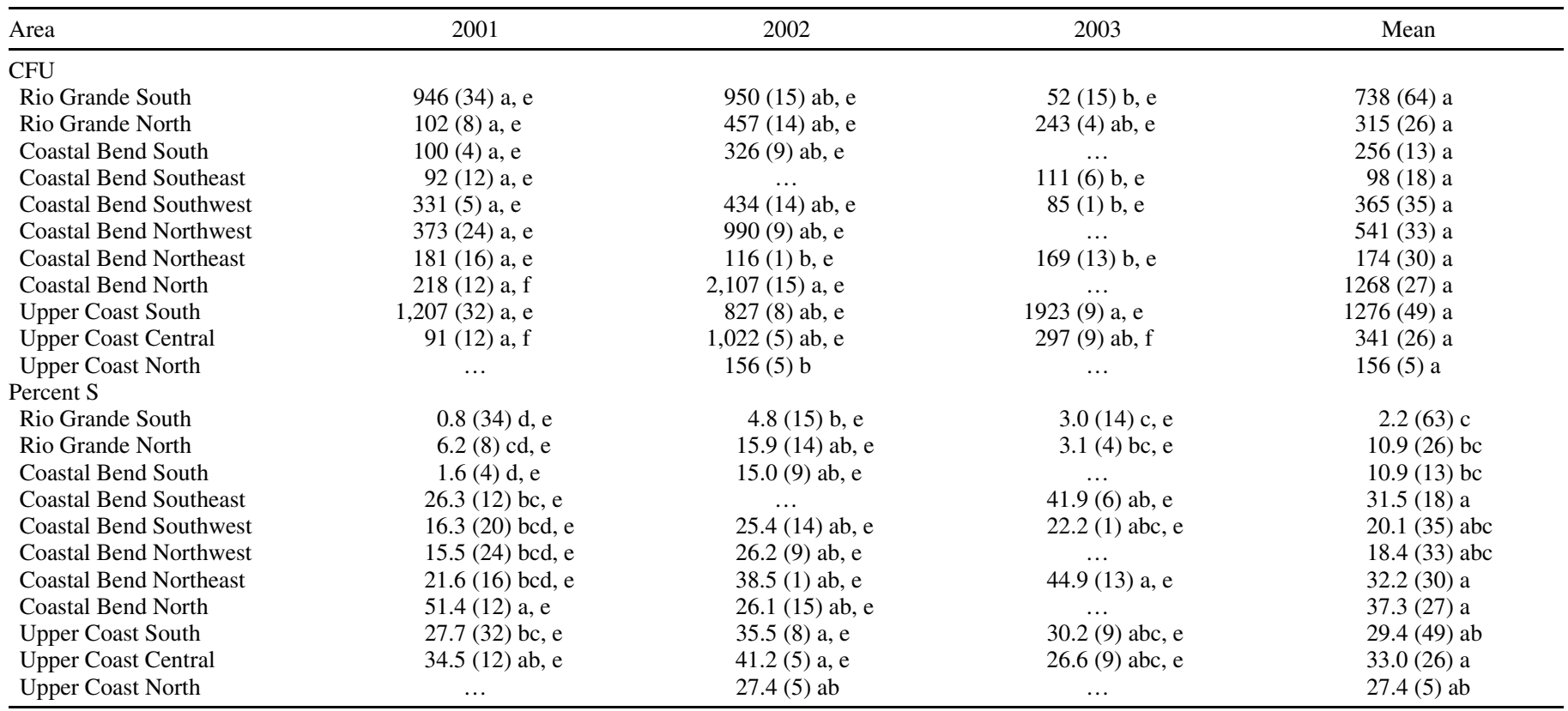

${ }^{\mathrm{z}}$ Numbers in parentheses $=$ number of samples analyzed. Averages with the same letter are not significantly different by Tukey's honestly significant difference test $(\alpha=0.05)$. Letters before the comma indicate differences among regions (rows) and letters following the comma indicate differences among years (columns). 
TABLE 3. Variation among regions, areas, and fields and within fields in Aspergillus flavus (CFU/g), percentage of isolates belonging to the $\mathrm{S}$ strain of A. flavus, (percent $\mathrm{S}$ ), and of soil texture as described by the percent of clay, silt, and sand in soils of South Texas ${ }^{2}$

\begin{tabular}{lrrcc}
\hline Variance component & df & Estimates & Variance $(\%)$ & $P>F$ \\
\hline Percent S & & & & \\
Among regions & 2 & 131.5 & 23.7 & $<0.0001$ \\
Among areas & 9 & 49.8 & 9.0 & $<0.0001$ \\
Among fields & 140 & 75.1 & 13.5 & 0.007 \\
Within fields (error) & 170 & 298.4 & 53.8 & $\ldots$ \\
CFU/g & & & & \\
Among regions & 2 & 0 & 0 & 0.0016 \\
Among areas & 9 & 73,815 & 6.1 & $<0.0001$ \\
Among fields & 140 & 581,545 & 48.4 & $<0.0001$ \\
Within fields (error) & 171 & 546,137 & 45.5 & $\ldots$ \\
Clay & & & & \\
Among regions & 2 & 0 & 0 & $<0.0001$ \\
Among areas & 9 & 105.3 & 34.1 & $<0.0001$ \\
Among fields & 139 & 166.2 & 53.7 & $<0.0001$ \\
Within fields (error) & 170 & 37.8 & 12.2 & $\ldots$ \\
Silt & & & & \\
Among regions & 2 & 5.2 & 5.2 & $<0.0001$ \\
Among areas & 9 & 20.0 & 19.9 & $<0.0001$ \\
Among fields & 139 & 47.6 & 47.5 & $<0.0001$ \\
Within fields (error) & 170 & 27.5 & 27.4 & $\ldots$ \\
Sand & & & & \\
Among regions & 2 & 0.3 & 0.1 & $<0.0001$ \\
Among areas & 9 & 160.1 & 33.3 & $<0.0001$ \\
Among fields & 139 & 275.7 & 57.4 & $<0.0001$ \\
Within fields (error) & 170 & 44.3 & 9.2 & $\ldots$ \\
\hline z df = degrees of freedom and $P>F=$ probability of the calculated $F$ \\
value.
\end{tabular}

covariogram range for both $\mathrm{CFU} / \mathrm{g}$ and percent $\mathrm{S}$ compared with fields cropped to cotton or sorghum. Fields previously cropped with corn presented the highest spatial variation for $\mathrm{CFU} / \mathrm{g}$ with a sill (partial sill + nugget) $=3,708,000$, whereas fields previously cropped with cotton presented the highest spatial variation for percent $S$ with a sill (partial sill + nugget) $=610$.

Ordinary kriging maps. The $\mathrm{S}$ strain constituted $>30 \%$ of the overall A. flavus community in the area extending from the central Coastal Bend to the central Upper Coast regions (Fig. 1A). The west Rio Grande Valley had the lowest $S$ strain incidence $(<10 \%)$. When spatial patterns were obtained individually by previous crop, fields that were cropped with cotton or sorghum the previous year had higher percentages of the $S$ strain (Fig. 1B to E) than fields cropped with corn. Most of the areas in Coastal Bend and Upper Coast had percentages of the S strain $>30 \%$ when only samples from fields previously cropped with cotton or sorghum were considered in the analysis, whereas most of the areas throughout South Texas had a percentage of S strain $<30 \%$ when only samples from corn fields were included.

Average quantities of $A$. flavus propagules were greatest, averaging $>500 \mathrm{CFU} / \mathrm{g}$, from the north Coastal Bend to the central Upper Coast. Areas within $50 \mathrm{~km}$ of the coast averaged $>1,000 \mathrm{CFU} / \mathrm{g}$ (Fig. 2A). Maps obtained from fields previously cropped to corn had the highest quantity of A. flavus, averaging $>500 \mathrm{CFU} / \mathrm{g}$ over most of South Texas and $>2,000 \mathrm{CFU} / \mathrm{g}$ in areas of the Rio Grande Valley and the Port Lavaca peninsula (Fig. 2C). Maps of fields previously cropped with sorghum (Fig. 1D) had populations averaging $<500 \mathrm{CFU} / \mathrm{g}$ throughout South Texas. Maps generated from fields cropped to cotton the previous season

TABLE 4. CFU/g and percentage of Aspergillus flavus isolates belonging to the $\mathrm{S}$ strain in soil planted the previous year to either cotton, corn, or sorghum from 2001 to $2003^{z}$

\begin{tabular}{|c|c|c|c|c|}
\hline \multirow[b]{2}{*}{ Previous crop } & \multicolumn{4}{|c|}{ South Texas regions } \\
\hline & Rio Grande & Coastal Bend & Upper Coast & South Texas \\
\hline \multicolumn{5}{|l|}{$\mathrm{CFU} / \mathrm{g}$} \\
\hline Cotton & $516(24) \mathrm{b}, \mathrm{d}$ & $531(46) \mathrm{b}, \mathrm{de}$ & 644 (36) ab, e & $566(106) b$ \\
\hline Sorghum & 198 (24) b, e & $138(52) \mathrm{b}, \mathrm{e}$ & 158 (10) b, e & $157(86) \mathrm{c}$ \\
\hline Mean & $865(56)$ e & $513(142) d$ & $921(69) \mathrm{e}$ & $\ldots$ \\
\hline \multicolumn{5}{|l|}{ Percent S } \\
\hline Mean & $5.1(56) \mathrm{d}$ & $26.1(142) \mathrm{e}$ & $31.2(69) \mathrm{e}$ & $\ldots$ \\
\hline
\end{tabular}

${ }^{\mathrm{z}}$ Numbers in parentheses $=$ number of samples analyzed. Averages with the same letter are not significantly different by Tukey's honestly significant difference test $(\alpha=0.05)$. Letters before the comma indicate differences among regions (rows) and letters following the comma indicate differences among years (columns).

TABLE 5. Pearson's correlation coefficients of the relationship of the quantity (CFU) and composition (percentage of Aspergillus flavus composed of the S strain = percent S) of A. flavus to soil texture variables (clay, silt and sand) from fields of South Texas ${ }^{\mathrm{z}}$

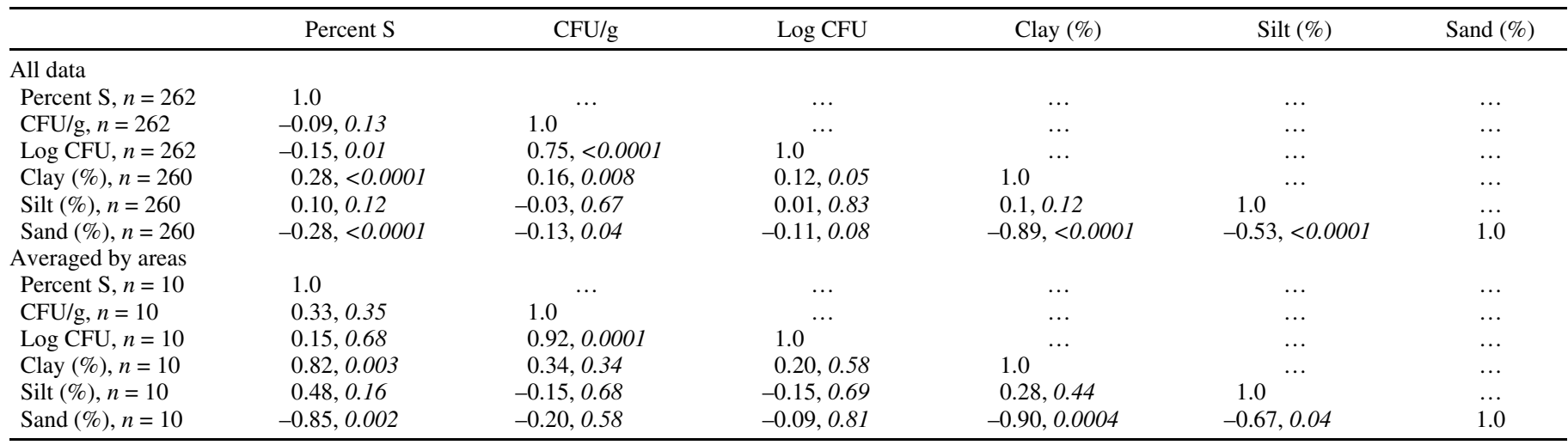

${ }^{\mathrm{z}}$ Samples from the South Rio Grande area (area 1) were excluded from the Pearson's correlation analysis because the incidence of S-strain isolates in this area was very low (2.2\%), causing insufficient variation for this variable in area 1. Normal font represents coefficient of correlation and italics represents probability of significance. 
were more variable among the areas in the magnitude of A. flavus population, with areas averaging $>500 \mathrm{CFU} / \mathrm{g}$ in the three regions (Fig. 1B).

Soil texture patterns varied across South Texas, with heavier soils (percent clay $>50 \%$ ) mainly in the eastern and northern part of the Coastal Bend to the south-central part of the Upper Coast and the lower part (southeast) of the Rio Grande Valley (Fig. 3A). Percentages of silt were $<30 \%$ across most of South Texas, with only the northern part of the Upper Coast and a small area in the eastern part of the Rio Grande Valley having between 30 and $40 \%$ silt (Fig. 3B). Lighter soils (percent sand $>50 \%$ ) were found from the Rio Grande Valley (except the lower part of the valley) to the southern and western part of the Coastal Bend area (Fig. 3C).

\section{DISCUSSION}

Variation in both A. flavus population density and strain composition in soils of South Texas may be influenced by various factors. Population density (CFU/g) varies mainly temporally, probably resulting from variation in weather conditions. Overall, in 2002, there was significantly more CFU/g than in either 2001 or 2003. Although, in our data, there were significant differences among regions for $\mathrm{CFU} / \mathrm{g}$, spatial variation at regional scales in CFU/g might not play an important role in aflatoxin contamination in South Texas. The Coastal Bend region displayed significantly lower population densities than the Upper Coast region; however, this difference might be due to the previous crop. A greater proportion of sampled fields in the Coastal Bend region had been cropped with sorghum than sampled fields in the Upper Coast (Table 4). Sorghum supports relatively lower A. flavus densities compared with corn or cotton. Furthermore, VCA in both the current study and a previous study in Arizona (26) agree with geostatistical analyses that population density (CFU/g) of $A$. flavus varies spatially, but mainly at small geographic scales among and within fields. This is consistent with a major component of variation in population density attributed to variation in crop types.

During the course of the current study, A. flavus strain structure in soils of South Texas presented significant spatial variation but not significant temporal variation. The Rio Grande Valley had a significantly lower percentage of the $\mathrm{S}$ strain than the Coastal Bend and Upper Coast. Overall percentages of the $\mathrm{S}$ strain did not differ significantly among the 3 years of study, although there were significant differences for the percent $S$ among seasons when analyses were performed individually by region. These differences might be attributed to spatial variation rather than to temporal variation. The Rio Grande Valley had a greater percent $S$ in 2002 and the Coastal Bend had significantly more percent $\mathrm{S}$ in 2003. However, these differences could be explained by increased sample numbers from areas within these regions where the $S$ strain is more prevalent. In the case of the Rio Grande Valley, a higher proportion of samples from the northern part of the Valley were taken in the 2002 season whereas, in the Coastal Bend area, a higher proportion of samples from the southeast and northeast areas were taken in the 2003 season.

In this study, both VCA and geostatistics partitioned variation among scales in a similar manner, if one considers that the sampling error and small-scale variability (replications within fields in this study) are represented by the nugget in geostatistics (19) and by the residual (error) in VCA, whereas the variability explained by larger scales will be defined by the variogram (covariogram) range in geostatistics and by the proportion of variance explained by each of the larger scales in VCA. In this study, all the variables that have a large residual (i.e., percent $\mathrm{S}$ and $\mathrm{CFU} / \mathrm{g}$ ) also have a large nugget effect, whereas those that have a smaller residual (i.e., percent clay, percent silt, and percent sand) present a smaller nugget effect. On the other hand, for variables that present long variogram ranges (i.e., percent $S$ ), an important proportion of the variance is explained by large (among regions) scales in VCA, whereas the variables with short variogram ranges (i.e., $\mathrm{CFU} / \mathrm{g}$ and percent silt) have none or a very small proportion of the variance explained by the among-regions and among-areas scales in VCA.

Both VCA and geostatistics indicate that approximately half of the variance for $\mathrm{S}$ strain incidence occur at the very small scale, which might be explained by both the within-fields spatial variation and the sampling error. An important proportion of the variation occurs at the large scale of among regions. These data are similar to those reported by Orum et al. (26) for Yuma, AZ, where most of the variance for S-strain incidence was explained by the small scales $(<5 \mathrm{~km})$ among fields and within fields, with some proportion explained by subregions. However, in that study, larger scales were not explored. In the present study, among fields has a larger scale (up to $25 \mathrm{~km}$ ) than the Arizona study (26), and this might contribute to the lower variation. Considering that among regions explains an important proportion of the variation in percent $S$, then some regions might be more conducive to the $S$ strain than others. Factors influencing $S$ strain incidence are not yet understood although, based on our study, we suggest that soil type and crop rotation may play roles.

There were significantly higher quantities of $A$. flavus propagules in soils from fields previously cropped with corn $(1,485 \mathrm{CFU} / \mathrm{g})$ than with cotton (566 CFU/g) and sorghum (157 CFU/g), and

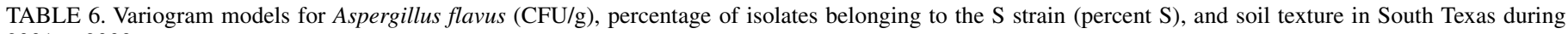
2001 to 2003

\begin{tabular}{|c|c|c|c|c|c|c|c|}
\hline Variable & Variography & Type & Lag distance $(\mathrm{m})$ & Nugget & Partial sill ${ }^{\mathrm{x}}$ & Range (m) & $\mathrm{IGF}^{\mathrm{y}}$ \\
\hline \multicolumn{8}{|l|}{$\mathrm{CFU} / \mathrm{g}$} \\
\hline All crops ${ }^{\mathrm{Z}}$ & Covariogram & Spherical & 16,000 & 896,000 & 532,000 & 35,100 & 0.009 \\
\hline Corn & Covariogram & Spherical & 18,000 & $2,124,000$ & $1,584,000$ & 30,000 & 0.005 \\
\hline Cotton & Covariogram & Spherical & 17,500 & 607,000 & 334,000 & 37,500 & 0.007 \\
\hline Sorghum & Covariogram & Spherical & 16,000 & 18,200 & 12,200 & 35,000 & 0.025 \\
\hline Others & Covariogram & Spherical & 15,700 & 131,000 & 37,400 & 44,000 & 0.003 \\
\hline \multicolumn{8}{|l|}{ Percent S } \\
\hline All crops & Covariogram & Spherical & 18,500 & 350 & 102 & 75,000 & 0.004 \\
\hline Corn & Covariogram & Spherical & 16,300 & 254 & 92 & 56,000 & 0.005 \\
\hline Cotton & Covariogram & Spherical & 17,800 & 420 & 190 & 69,000 & 0.002 \\
\hline Sorghum & Covariogram & Spherical & 18,300 & 312 & 208 & 75,000 & 0.017 \\
\hline Others & Variogram & Spherical & 22,000 & 58 & 190 & 36,500 & 0.014 \\
\hline \multicolumn{8}{|l|}{ Texture } \\
\hline Clay $(\%)$ & Covariogram & Spherical & 14,000 & 90 & 182 & 54,000 & 0.012 \\
\hline Silt (\%) & Variogram & Spherical & 13,500 & 37 & 48 & 33,000 & 0.046 \\
\hline Sand (\%) & Variogram & Spherical & 12,000 & 128 & 308 & 50,000 & 0.012 \\
\hline
\end{tabular}

${ }^{x}$ Partial sill is the sill minus the nugget. It represents the spatially dependent variance.

${ }^{y}$ IGF $=$ indicative goodness of fit based on a weighted mean square standardized, where values close to zero indicate good fit.

${ }^{\mathrm{z}}$ Crop that was cultivated the previous year. 
significantly higher percent $\mathrm{S}$ in soils from fields previously cropped with cotton $(28.6 \%)$ than with corn (17.0\%). Geostatistical analyses confirmed these trends with higher sill values in corn for $\mathrm{CFU} / \mathrm{g}$ and in cotton for percent $\mathrm{S}$ and a higher average A. flavus density (CFU/g) for corn and higher average percent $\mathrm{S}$ for cotton. Thus, in South Texas, crop rotation influenced both population density and incidence of the $\mathrm{S}$ strain, with corn favoring a high population density of A. flavus and cotton and sorghum favoring a high $\mathrm{S}$ strain incidence. Cotton previously was suggested to favor the $S$ strain based on greenhouse studies (17). However, this is contrary to what Orum et al. (26) found in Yuma, AZ, where they observed that S-strain incidence was not dependent on crop sequence and concluded that S-strain incidence was dependent on factors other than crop rotation which extended beyond field boundaries. However, corn rotations were not included in the previous study (26). This rotation is shown in the current study to favor the common L strain in South Texas. Based on data presented in the current study, crop rotation influenced S-strain incidence at the among-fields scale in South Texas.

The A. flavus S strain had patchy distribution on large scales, with some areas or regions with higher incidences of the $S$ strain $(25,26)$. However, factors favoring strain $S$ over regional scales have not been characterized. Orum et al. (26) mentioned soil type as a potential influence on strain composition at larger scales than
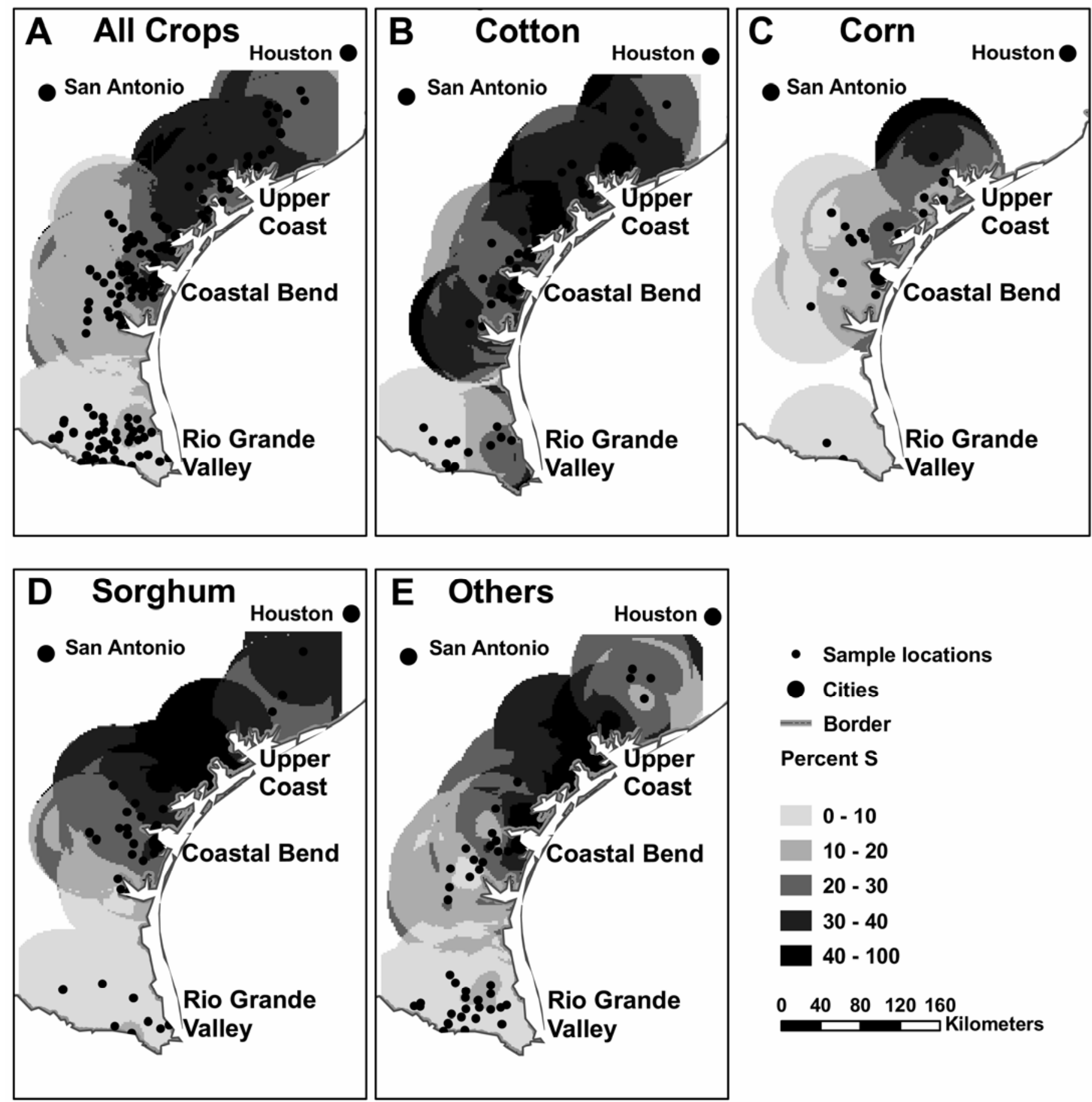

- Sample locations

- Cities

- Border

Percent S

0 - 10

$10-20$

20 - 30

$30-40$

$40-100$

$\begin{array}{lllll}0 & 40 & 80 & 120 & 160\end{array}$

Fig. 1. Estimated spatial patterns of the incidence of Aspergillus flavus S strain in South Texas soils sorted by the previous year crop. Soils were sampled March 2001 through March 2003. Estimations of percent S are based upon Block Kriging (2-by-2-km blocks), which only included fields where the previous year crop was A, all crops, B, cotton, C, corn, D, sorghum, or E, other crops. A search neighborhood of $60 \mathrm{~km}$ and a maximum of 40 sample points (fields) were used to generate the Kriging estimates. 
among fields. Correlation and geostatistical analyses in the present study indicate that soil type might be a factor affecting $A$. flavus strain composition at regional (among-areas) scales, but not among regions (in the current study, areas extend $>25 \mathrm{~km}$ and regions $>100 \mathrm{~km}$ ). Percent $\mathrm{S}$ correlated positively with percent clay and negatively with percent sand, but only when the Rio Grande Valley region, with low S strain incidence, was not included in the correlation analysis. Likewise, maps of both percent $\mathrm{S}$ strain and soil type variables, obtained by kriging, show that those areas with heavy (clay) soils, except for the Rio Grande Valley region, also are the areas with the highest $\mathrm{S}$ strain incidence. This indicates that heavy soils might favor the $S$ strain within regions but not among regions. Factors influencing S-strain incidence among regions have not been described. However, crop rotation may be influencing $A$. flavus strain composition at regional levels. Crop rotations in the Coastal Bend and Upper Coast regions are mainly cotton, sorghum, and corn, whereas crop rotation in the Rio Grande Valley region is more diverse, including sugarcane, citrus, and many vegetable crops such as cucurbits, onion, and crucifers in addition to cotton, corn, and sorghum. The main crops in the Coastal Bend and Upper Coast are known A. flavus hosts, with cotton and sorghum favoring $S$ strain incidence, whereas influences on A. flavus by many crops in the Rio Grande Valley are not known.
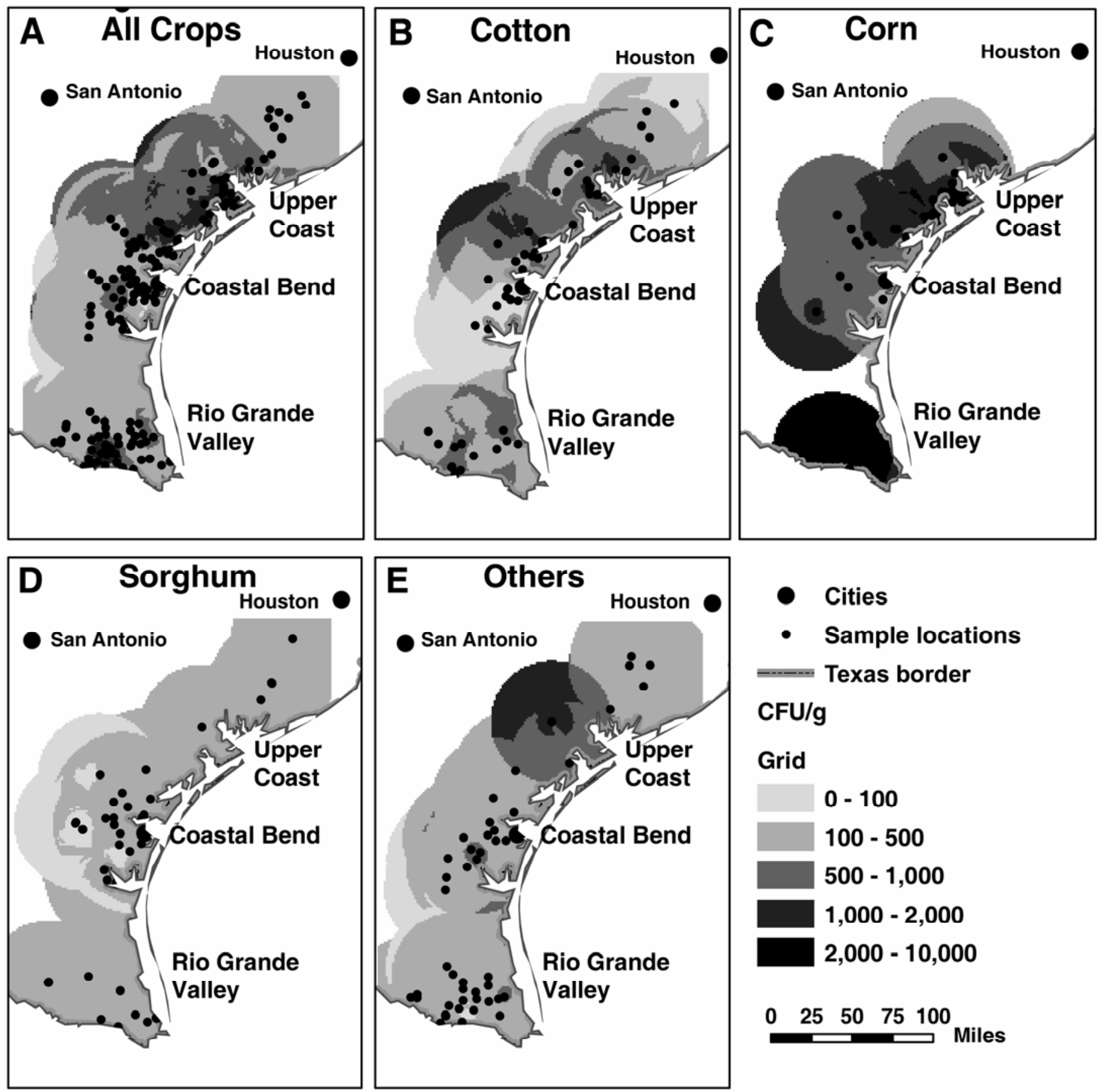

- Cities

- Sample locations

….. Texas border

CFU/g

Grid

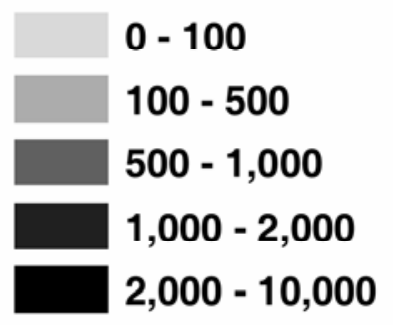

$\begin{array}{lllll}0 & 25 & 50 & 75 & 100\end{array}$

Fig. 2. Estimated spatial patterns of CFU of Aspergillus flavus per gram of soil (CFU/g) in South Texas fields sorted by the previous year crop. Soils were sampled March 2001 through March 2003. Estimations of CFU/g are based upon Block Kriging (2-by-2-km blocks), which only included fields where the previous year crop was A, all crops, B, cotton, C, corn, D, sorghum, or E, other crops. A search neighborhood of $60 \mathrm{~km}$ and a maximum of 40 sample points (fields) were used to generate the Kriging estimates. 

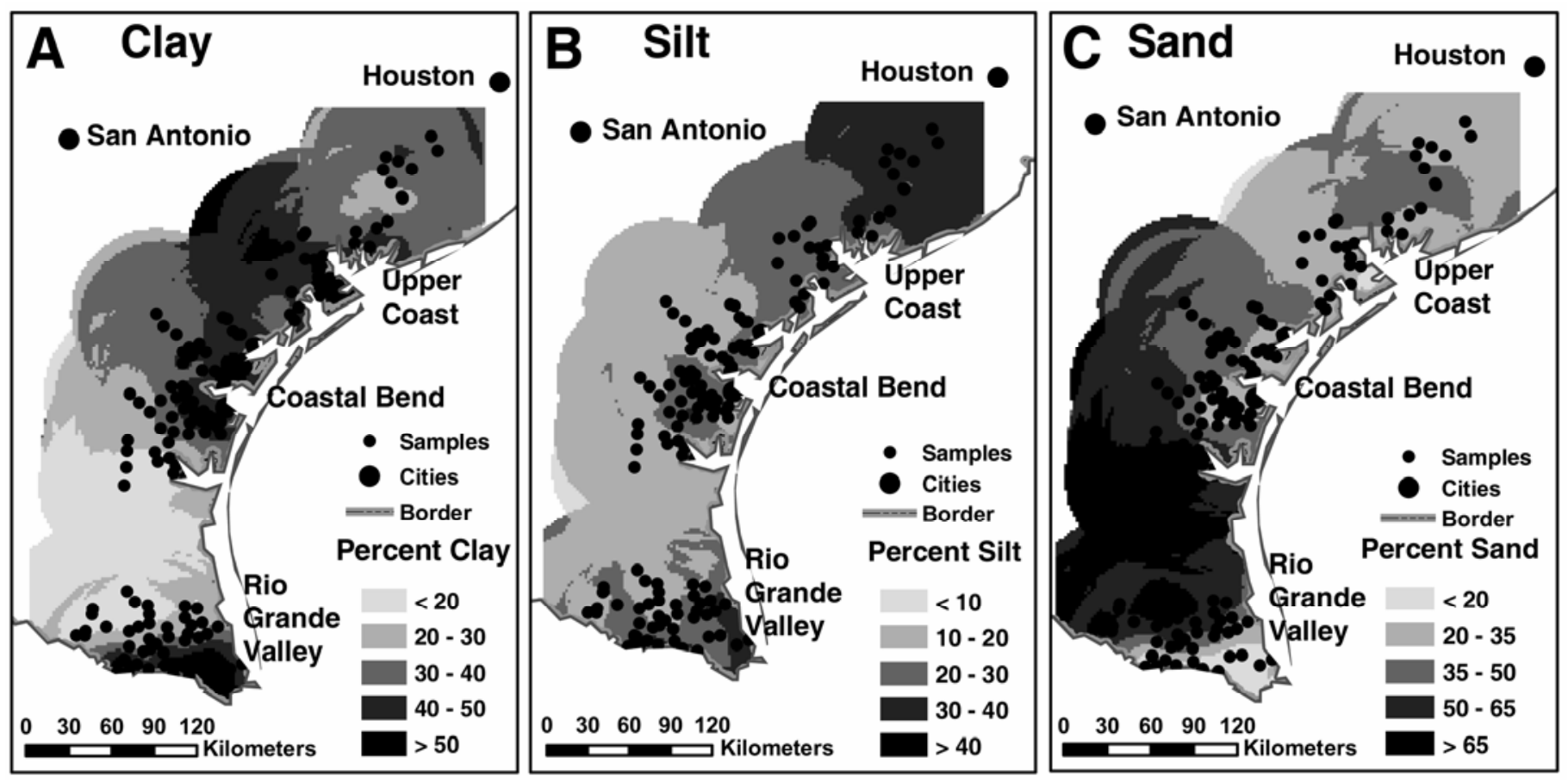

Fig. 3. Estimated spatial patterns of the soil texture variables A, percent clay, B, percent silt, and $\mathbf{C}$, percent sand in South Texas. Estimations of percentages of clay, silt, and sand are based upon Block Kriging (2-by-2-km blocks). A search neighborhood of $60 \mathrm{~km}$ and a maximum of 40 sample points (fields) were used to generate the Kriging estimates.

The $\mathrm{S}$ strain of A. flavus is an important cause of aflatoxin contamination in Arizona (4,6,17). Based on maps of aflatoxin contamination (20) and the incidence of the S strain in South Texas, areas with high aflatoxin levels also have high incidences of the S strain. Interestingly, on average, soils of all of the highaflatoxin areas studied contain high percent clay and low percent sand. Although there are some high-clay soils adjacent to the Rio Grande River, they are in an area with neither high levels of aflatoxin (20) nor high incidences of the S strain (Fig. 1). Taken together, these observations suggest that soil type influences $\mathrm{S}$ strain incidence within regions but not among regions. Heavy soils might favor aflatoxin contamination in South Texas by both favoring the $\mathrm{S}$ strain, which possesses high aflatoxin-producing potential (6), and favoring growth of A. flavus on the crop by retaining high humidity and, thus, favoring the second phase of aflatoxin contamination $(3,5,7,31)$.

\section{ACKNOWLEDGMENTS}

This work was supported in part by grants from the Cotton Foundation, the Texas State Support Program of Cotton Incorporated, the Texas Cottonseed Crushers Association, and the United States Department of Agriculture Multi-Crop Aflatoxin Working Group. We thank J. Nunley and the South Texas Cotton and Grain Association for assistance in several aspects of the work and S. Williams and L. Turner for technical assistance.

\section{LITERATURE CITED}

1. Allcroft, R., and Carnaghan, R. B. A. 1963. Groundnut toxicity: an examination for toxin in human food products from animals fed toxic groundnut meal. Vet. Rec. 75:259-263.

2. Bayman, P., and Cotty, P. J. 1993. Genetic diversity in Aspergillus flavus: Association with aflatoxin production and morphology. Can. J. Bot. 71:23-31.

3. Bock, C. H., and Cotty, P. J. 1999. The relationship of gin date to aflatoxin contamination of cottonseed in Arizona. Plant Dis. 83:279-285.

4. Cotty, P. J. 1989. Virulence and cultural characteristics of two Aspergillus flavus strains pathogenic on cotton. Phytopathology 79:808-814.

5. Cotty, P. J. 1991. Effect of harvest date on aflatoxin contamination of cottonseed. Plant Dis. 75:312-314.
6. Cotty, P. J. 1997. Aflatoxin-producing potential of communities of Aspergillus section Flavi from cotton producing areas in the United States. Mycol. Res. 101:698-704.

7. Cotty, P. J. 2001. Cottonseed losses and mycotoxins. Pages 9-13 in: Compendium of Cotton Diseases. 2nd ed. T. L. Kirkpatrick and C. S. Rothrock, eds. The American Phytopathological Society, St. Paul, MN.

8. Cotty, P. J., Bayman, P., Egel, D. S., and Elias, K. S. 1994. Agriculture, aflatoxins and Aspergillus. Pages 1-27 in: The Genus Aspergillus: From Taxonomy and Genetics to Industrial Application. K. A. Powel, A. Renwick, and J. F. Peverdy, eds. Plenum Press, New York.

9. Cotty, P. J., Jaime-Garcia, R., and Kobbeman, K. 2001. The S strain of $A$. flavus in South Texas. (Abstr.) Phytopathology 91(suppl.):S19.

10. Cressie, N. 1993. Geostatistics: A tool for environmental modelers. Pages 414-421 in: Environmental Modeling with GIS. M. F. Goodchild, B. O. Parks, and L. T. Steyaert, eds. Oxford University Press, New York.

11. Deutsch, C. V., and Journel, A. G. 1992. GSLIB Geostatistical Software Library and User's Guide. Oxford University Press, New York.

12. Doster, M. A., and Michailides, T. J. 1994. Development of Aspergillus molds in litter from pistachio tress. Plant Dis. 78:393-397.

13. Doster, M. A., Michailides, T. J., and Morgan, D. P. 1996. Aspergillus species and mycotoxins in figs from California orchards. Plant Dis. 80:484-489.

14. Egel, D. S., Cotty, P. J., and Elias, K. S. 1994. Relationships among isolates of Aspergillus sect. Flavi that vary in aflatoxin production. Phytopathology 84:906-912.

15. Ehrlich, K. C., Montalbano, B. G., and Cotty, P. J. 2003. Sequence comparison of aflR from different Aspergillus species provides evidence for variability in regulation of aflatoxin production. Fungal Genet. Biol. 38:63-74.

16. Fedra, K. 1993. GIS and environmental modeling. Pages 35-50 in: Environmental Modeling with GIS. M. F. Goodchild, B. O. Parks, and L. T. Steyaert, eds. Oxford University Press, New York.

17. Garber, R. K., and Cotty, P. J. 1997. Formation of sclerotia and aflatoxins in developing cotton bolls infected by the $\mathrm{S}$ strain of Aspergillus flavus and potential for biocontrol with an atoxigenic strain. Phytopathology 87:940-945.

18. Horn, B. W., and Dorner, J. W. 1998. Soil populations of Aspergillus species from section Flavi along a transect through peanut-growing regions of the United States. Mycologia 90:767-776.

19. Isaaks, E. H., and Srivastava, R. M. 1989. An Introduction to Applied Geostatistics. Oxford University Press, New York.

20. Jaime-Garcia, R., and Cotty, P. J. 2003. Aflatoxin contamination in commercial cottonseed in South Texas. Phytopathology 93:1190-1200.

21. Journel, A. G. 1989. Fundamentals of Geostatistics in Five Lessons. American Geophysical Union, Washington, DC. 
22. Myers, D. E. 1991. Interpolation and estimation with spatially located data. Chemom. Intell. Lab. Syst. 11:209-228.

23. Nelson, M. R., Orum, T. V., Jaime-Garcia, R., and Nadeem, A. 1999. Applications of geographic information systems and geostatistics in plant disease epidemiology and management. Plant Dis. 83:308-319.

24. Novas, M. V., and Cabral, D. 2002. Association of mycotoxin and sclerotia production with compatibility groups in Aspergillus flavus from peanut in Argentina. Plant Dis. 86:215-219.

25. Orum, T. V., Bigelow, D. M., Cotty, P. J., and Nelson, M. R. 1999. Using predictions based on geostatistics to monitor trends in Aspergillus flavus strain composition. Phytopathology 89:761-769.

26. Orum, T. V., Bigelow, D. M., Nelson, M. R., Howell, D. R., and Cotty, P. J. 1997. Spatial and temporal patterns of Aspergillus flavus strain composition and propagules density in Yuma County, Arizona, soils. Plant Dis. 81:911-916.

27. Pannatier, Y. 1996. VARIOWIN: Software for Spatial Data Analysis in 2D. Springer-Verlag, New York.

28. Park, D. L., Lee, L. S., Price, R. L., and Pohland, A. E. 1988. Review of the decontamination of aflatoxins by ammoniation: Current status and regulation. J. Assoc. Off. Anal. Chem. 71:685-703.

29. Park, D. L., and Troxell, T. C. 2002. U.S. perspective in mycotoxin regulatory issues. Pages 277-285 in: Mycotoxins and Food Safety, Advances in Experimental Medicine and Biology. Vol. 504. J. W. DeVries, M. W. Trucksess, and L. S. Jackson, eds. Kluwer Academic/Plenum
Publishers, New York.

30. Russell, T. E. 1982. Aflatoxins in cottonseed. Univ. Ariz. Coop. Ext. Serv. Publ. Q422.

31. Russell, T. E., Watson, T. F., and Ryan, G. F. 1976. Field accumulation of aflatoxin in cottonseed as influenced by irrigation termination dates and pink bollworm infestation. Appl. Environ. Microbiol. 31:711-713.

32. Saito, M., Tsuruta, O., Siriacha, P., Kawasugi, S., Manabe, M., and Buangsuwon, D. 1986. Distribution and aflatoxin productivity of the atypical strains of Aspergillus flavus isolated from soils in Thailand. Proc. Jpn. Assoc. Mycotoxicol. 24:41-46.

33. Schroeder, H. W., and Boller, R. A. 1973. Aflatoxin production of species and strains of the Aspergillus flavus group isolated from field crops. Appl. Microbiol. 25:885-889.

34. Seem, R. C. 1993. Geographic information systems for localized pest predictions. Bull. OEPP (Organ. Eur. Mediterr. Prot. Plant.) 23:639-646.

35. Tan, K. H. 1996. Soil Sampling, Preparation, and Analysis. Marcel Dekker, Inc., New York.

36. van Egmond, H. P. 1989. Aflatoxin M1: Occurrence, toxicity, regulation. Pages 11-55 in: Mycotoxins in Dairy Products. H. P. van Egmond, ed. Elsevier Applied Science, New York.

37. van Egmond, H. P. 2002. Worldwide regulations for mycotoxins. Pages 257-269 in: Mycotoxins and Food Safety, Advances in Experimental Medicine and Biology. Vol. 504. J. W. DeVries, M. W. Trucksess, and L. S. Jackson, eds. Kluwer Academic/Plenum Publishers, New York. 